\title{
Dilatation with progressively larger balloons for severe stenosis of the pulmonary valve presenting in the late neonatal period and early infancy
}

\author{
SHAKEEL A QURESHI, EDMUND J LADUSANS, ROBIN P MARTIN* \\ From the Departments of Paediatric Cardiology, Royal Liverpool Children's Hospital, Liverpool; and Guy's \\ Hospital, London
}

SUMMARY Balloon dilatation in infants with severe pulmonary valve stenosis may not be a straightforward procedure once the arterial duct has closed. Balloon dilatation was attempted in three neonates and infants. In an 11 week old infant hypotension and bradycardia developed shortly after a 5 French end hole catheter was passed through the severely stenosed pulmonary valve. An emergency Waterston shunt was subsequently performed, but he died three days later. After this experience the technique was modified so that progressively larger balloons were used for dilatation in two infants, aged one and three weeks, with severe pulmonary valve stenosis in whom the arterial duct had closed. It was successful in both.

Percutaneous balloon dilatation is now a widely accepted treatment for pulmonary valve stenosis in children and adults. ${ }^{12}$ Its application to the treatment of severe stenosis of the pulmonary valve in early infancy is less well established. There have been several reports of successful balloon dilatation in this age group. ${ }^{3-7}$ The procedure is generally thought to be safe and effective, especially when the arterial duct is patent. When the arterial duct is closed, however, balloon dilatation may not be straightforward. The purpose of this paper is to highlight the complications associated with this procedure and to suggest modifications of technique for avoiding these complications.

\section{Patients and methods}

Percutaneous balloon dilatation was attempted for severe pulmonary valve stenosis in three neonates and infants. The group consisted of an 11 week old boy (born at 32 weeks' gestation) (case 1), a one week old boy (case 2), and a three week old girl (case 3) (table).

Requests for reprints to Dr Shakeel A Qureshi, Department of Paediatric Cardiology, Guy's Hospital, St Thomas Street, London SE1 9RT.

*Present addreas: Bristol Royal Hospital for Sick Children, St Michael's Hill, Bristol BS2 8BJ.

Accepted for publication 17 May 1989
Case 1 required assisted ventilation for 25 days after birth because of hyaline membrane disease. His chest radiograph then showed cystic changes caused by pulmonary interstitial emphysema in the right lung. He was referred because of a harsh ejection systolic murmur associated with congestive cardiac failure. Non-invasive studies with cross sectional and Doppler echocardiography showed severe pulmonary valve stenosis with an estimated transvalvar gradient of $81 \mathrm{~mm} \mathrm{Hg}$, which increased to 144 $\mathrm{mm} \mathrm{Hg}$ over the next three weeks.

Case 2 presented with congestive cardiac failure and non-invasive investigations showed severe pulmonary valve stenosis with an estimated transvalvar gradient of $81 \mathrm{~mm} \mathrm{Hg}$.

Case 3 presented with mild cyanosis and breathlessness. Investigations showed severe pulmonary valve stenosis and a transvalvar gradient of $115 \mathrm{~mm} \mathrm{Hg}$.

TECHNIQUE OF CARDIAC CATHETERISATION AND BALLOON DILATATION

Cardiac catheterisation was performed percutaneously by the femoral venous and arterial routes under general anaesthesia. After measurement of the intracardiac saturations and pressures, right ventricular angiography was performed in all the patients. This confirmed a severely stenosed pulmonary valve. The pulmonary valve "annulus" was measured on the lateral projection of the angiogram. The dimensions of the angiography catheter were 
Table Data on three infants treated with balloon dilatation

\begin{tabular}{|c|c|c|c|c|c|c|c|}
\hline Case & $\begin{array}{l}\text { Age at } \\
B D(w k)\end{array}$ & $\begin{array}{l}\text { Weight at } \\
B D(\mathrm{~kg})\end{array}$ & $\begin{array}{l}R V \text { systolic } \\
\text { pressure at } \\
\text { cath (mom } \mathbf{H g} \text { ) }\end{array}$ & $\begin{array}{l}L V \text { systolic } \\
\text { pressure at } \\
\text { cath }(\operatorname{mom} \mathrm{Hg})\end{array}$ & $\begin{array}{l}R V: L V \\
\text { systolic ratio }\end{array}$ & $P V A(\mathrm{~mm})$ & $\begin{array}{l}B: A \\
\text { ratio }\end{array}$ \\
\hline $\begin{array}{l}1 \\
2 \\
3\end{array}$ & $\begin{array}{r}11 \\
1 \\
3\end{array}$ & $\begin{array}{l}2 \cdot 4 \\
4 \cdot 2 \\
3 \cdot 7\end{array}$ & $\begin{array}{l}240 \\
125 \\
135\end{array}$ & $\begin{array}{r}120 \\
95 \\
85\end{array}$ & $\begin{array}{l}2 \\
1.3 \\
1.6\end{array}$ & $\begin{array}{l}\overline{9} \\
8\end{array}$ & $\begin{array}{l}\overline{1 \cdot 4} \\
1 \cdot 25\end{array}$ \\
\hline
\end{tabular}

B:A, balloon:annulus ratio; BD, balloon dilatation; LV, left ventricle; PVA, diameter of pulmonary valve "annulus"; RV, right ventricle; $\overrightarrow{0}$ cath, catheterisation.

used to calculate the magnification factor. The arterial duct was closed in all three patients. The haemodynamic data are given in the table.

In case 1, a 5 French multipurpose end hole catheter was passed into the right ventricle. The patient remained haemodynamically stable while attempts were made to cross the pulmonary valve. Eventually, after the valve was crossed with a tip deflector wire in the catheter, the catheter was rapidly positioned in the proximal left pulmonary artery. The gradient across the pulmonary valve was $220 \mathrm{~mm} \mathrm{Hg}$. A 0.018 inch diameter floppy tipped exchange guide wire was quickly introduced through the catheter and placed in the distal left pulmonary artery. The patient developed rapidly progressive bradycardia and hypotension with pronounced ST segment depression on the electrocardiogram. The catheter was withdrawn to the right atrium, leaving the guide wire in the pulmonary artery, while external cardiac massage was started. Bradycardia persisted and so the guide wire was also removed. Subsequently, a stable cardiac rhythm was achieved but the infant remained hypotensive and hypoxic. An emergency Waterston shunt was performed, but he remained hypotensive and died three days later.

Necropsy confirmed severe pulmonary valve stenosis (figure) with a pulmonary valve orifice diameter of 1.5-2 mm (the external diameter of the catheter used was $1.7 \mathrm{~mm}$ ). There was considerable hypertrophy of the right ventricle with muscular narrowing of the outflow tract. The arterial duct was closed.

After the complications encountered in case 1 , we modified the technique of balloon dilatation. The pulmonary valve was initially crossed with a 0.014 inch floppy exchange guide wire (Schneider-Shiley AG) in case 2 and 0.018 inch floppy exchange guide wire in case 3. But because it was not possible to pass a 5 French end hole catheter over the guide wire through the valve orifice without causing hypotension, arterial desaturation, and bradycardia, a 4 French end hole catheter (William Cook, Europe) was manipulated over the guide wire into the proximal left pulmonary artery in case 2 and into the distal left pulmonary artery in case 3.

In case 2, a $3 \mathrm{~mm}$ diameter low profile coronary angioplasty balloon catheter on 4.3 French shaft $\stackrel{\vec{\omega}}{\circ}$ (Meadox Surgimed) was passed over the guide wire and the pulmonary valve orifice was dilated. This or resulted in subsequent easier positioning of the $4 \stackrel{N}{N}$ French end hole catheter in the distal left pulmonary $\dot{\omega}$ artery, where a 0.018 inch exchange guide wire was $\overrightarrow{ }$ placed. This facilitated the passage of progressively 은 larger catheters (5 French), guide wires (0.020 inch and 0.035 inch) and balloon catheters across the $\bigcirc$

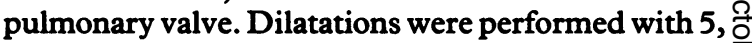
8,10 , and finally $13 \mathrm{~mm}$ diameter balloon catheters (Schneider Medintag AG). The constriction caused by the stenosed valve was completely abolished by the last balloon inflation.

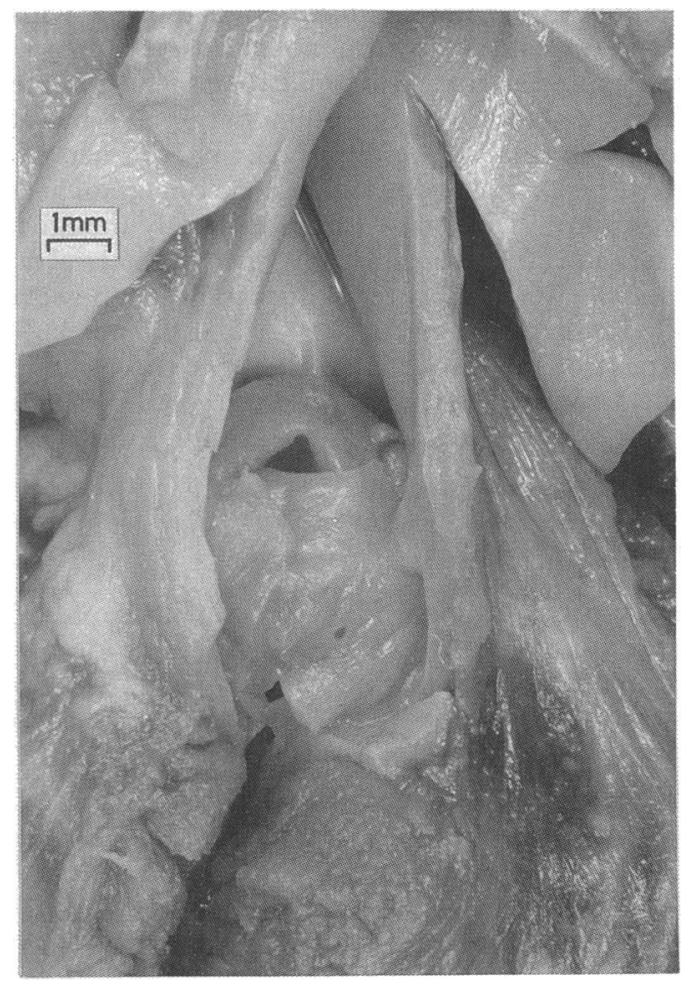

Figure Necropsy specimen showing the stenosed pulmonary valve with orifice diameter of $1.5-2.0 \mathrm{~mm}$. The right ventricular outflow tract and anterior wall of the pulmonary trunk have been opened to view the valve. 
In case 3, a $4.2 \mathrm{~mm}$ diameter balloon catheter on 4.3 French shaft (Schneider-Medintage AG) was positioned across the pulmonary valve and the balloon was inflated several times. The balloon catheter was replaced by a 5 French end hole catheter and a 0.021 inch exchange guide wire was positioned in the distal left pulmonary artery. This allowed a $6 \mathrm{~mm}$ diameter balloon catheter on a 5 French shaft (Schneider-Medintag) to be placed across the valve and the inflations repeated. Subsequently, the balloon catheter was replaced by the 5 French end hole catheter and the guide wire by a 0.035 inch exchange guide wire. A balloon catheter of $10 \mathrm{~mm}$ diameter on a 7 French shaft (Schneider-Medintag) was advanced over the wire and the inflations repeated until the constriction of the pulmonary valve was abolished. Both the patients were electively ventilated after the procedure for 24-48 hours.

\section{Results}

In cases 2 and 3, the procedure was well tolerated with only transient hypoxia, bradycardia, and hypotension with each balloon dilatation. Four different sized balloons were used in case 2 and three in case 3.

At the end of the procedure, in case 2 , the right ventricular systolic pressure was $45 \mathrm{~mm} \mathrm{Hg}$ compared with the femoral artery systolic pressure of 90 $\mathrm{mm} \mathrm{Hg}$. The peak to peak systolic pressure gradient across the pulmonary valve was $15 \mathrm{~mm} \mathrm{Hg}$. In case 3, the pulmonary artery pressure was $25 / 13 \mathrm{~mm} \mathrm{Hg}$ and the right ventricular systolic pressure was 125 $\mathrm{mm} \mathrm{Hg}$; the gradient across the right ventricular outflow (at infundibular level) was $100 \mathrm{~mm} \mathrm{Hg}$. The brachial artery systolic pressure was $95 \mathrm{~mm} \mathrm{Hg}$.

Case 2 was discharged home four days and case 3 two weeks after balloon dilatation. In case 3, serial Doppler studies showed a gradual reduction in the transvalvar gradient to $16 \mathrm{~mm} \mathrm{Hg}$ before discharge.

At the latest follow up, in each patient eight months after balloon dilatation, both the infants were symptom free and thriving. Doppler ultrasound showed an estimated residual gradient across the pulmonary valve of $13 \mathrm{~mm} \mathrm{Hg}$ in case 2 and 16 $\mathrm{mm} \mathbf{H g}$ in case 3 .

\section{Discussion}

Balloon dilatation of the pulmonary valve for pulmonary valve stenosis is reported to be safe and effective in neonates, infants, and children. ${ }^{3-6}$ The first case in this report shows the difficulties and potential hazards of passing a catheter through a severely stenosed pulmonary valve. In the early neonatal period a patent arterial duct provides an alternative source of pulmonary blood flow when the pulmonary valve orifice is occluded by a catheter or an inflated balloon. This may not be the case in the late neonatal period and early infancy, when the arterial duct has closed. It is in this group of patients that balloon dilatation may be less than straightforward. Nevertheless, the problems are not insurmountable and can be overcome by technical modifications.

Manoeuvring of the catheter across the severely narrowed pulmonary valve can prove difficult. In such patients, small diameter floppy guide wires are invaluable for the rapid placement of the wire and the catheter across the valve. Shortly after the catheter was placed in the pulmonary artery in case 1 , the infant deteriorated haemodynamically. We believe that this was the result of total occlusion of the valve orifice by the catheter. Necropsy did not show any evidence of trauma to the outflow tract or pericardial tamponade. The orifice diameter of the pulmonary valve was similar to the external diameter of the catheter. The choice of the optimum treatment in this infant was difficult. In view of the severe right ventricular hypertension, a closed arterial duct and, in particular, the severe lung abnormalities, we considered it preferable to attempt percutaneous balloon dilatation rather than operation. It is debatable whether a surgical approach would have been advantageous.

Our experience with case 1 prompted us to modify our technique. In the next two cases the pulmonary valve was crossed with a 0.014 or 0.018 inch guide wire and an end hole catheter, usually of 4 French size, was only manoeuvred across the valve to help position the guide wire quickly in the distal left pulmonary artery and the catheter was then rapidly withdrawn to the right atrium, thus preventing any appreciable obstruction of the pulmonary blood flow. In both cases 2 and 3 , we were unable to advance a 5 French end hole catheter through the pulmonary valve orifice. The first balloon inflation, we believe, is of crucial importance to the safety and the success of the rest of the procedure. We attempted dilatation initially with a smaller diameter $(3 \mathrm{~mm})$ coronary angioplasty or $4.2 \mathrm{~mm}$ diameter balloon catheter. This resulted in an increase in the valve orifice to effectively twice its original diameter, thus reducing the risks of compromising the pulmonary blood flow and facilitating the passage of subsequent balloon catheters. After this, we dilated the valve with balloon catheters of gradually increasing diameter.

It is conceivable that, in case 2 , a satisfactory outcome could still have resulted with dilatation up to the $10 \mathrm{~mm}$ diameter (balloon to "annulus" ratio of $1.1)$ balloon rather than $13 \mathrm{~mm}$ (ratio 1.4 ), thus reducing the cost of the procedure. However, we set 
out to achieve a final balloon to "annulus" ratio of $1 \cdot 2-1 \cdot 4$. While a balloon to "annulus" ratio of $<1.0$ may be effective initially, Rao reported that residual transvalvar gradients were significantly lower if the balloon to "annulus" ratio was $>1 \cdot 0 .{ }^{8}$ Furthermore, even with a ratio of $1 \cdot 0-1 \cdot 2$, recurrence of pulmonary valve stenosis requiring repeat balloon dilatation was more likely than when the ratio was $1 \cdot 2-1 \cdot 4$. In both cases 2 and 3 the excellent initial results have been maintained. In this age group, we found that progressive balloon dilatation was better than attempting to dilate the valve with one balloon $20-40 \%$ larger than the "annulus".

Our cases highlight the difficulties and complications associated with the management of severe stenosis of the pulmonary valve in early infancy when the arterial duct has closed. We believe that with attention to the technique and by using smaller floppy guide wires and smaller balloon catheters, of gradually increasing size, balloon dilatation can be safely and effectively performed in patients with severe pulmonary valve stenosis presenting in the late neonatal period and early infancy.

We are grateful to Miss Roxane McKay, who performed the shunt operation in case 1 and to $\mathrm{Dr}$ Audrey Smith for her comments on the necropsy and assistance with the photography of the specimen of the same case.

\section{References}

1 Kan JS, White RI Jr, Mitchell SE, Anderson JH, Gardner TJ. Percutaneous transluminal balloon valvuloplasty for pulmonary valve stenosis. Circulation 1984;69:554-60.

2 Kveselis DA, Rocchini AP, Snider AR, Rosenthal A, Crowley DC, Dick M. Results of balloon valvuloplasty in the treatment of congenital valvar pulmonary stenosis in children. Am J Cardiol 1985;56: 527-32.

3 Rey C, Marache P, Francart C, Dupuis C. Percutaneous transluminal balloon valvuloplasty of congenital pulmonary valve stenosis with a special report on infants and neonates. J Am Coll Cardiol 1988;11:815-20.

4 Zeevi B, Keane JF, Fellows KE, Lock JE. Balloon dilatation of critical pulmonary stenosis in the first week of life. J Am Coll Cardiol 1988;11:821-4.

5 Tynan M, Baker EJ, Rohmer J, et al. Percutaneous balloon pulmonary valvuloplasty. $B r$ Heart $J$ 1985; 53:520-4.

6 Sullivan ID, Robinson PJ, Macartney FJ, et al. Percutaneous balloon valvuloplasty for pulmonary valve stenosis in infants and children. Br Heart $J$ 1985;54:435-41.

7 Radtke W, Keane JF, Fellows KE, Lang P, Lock JE. Percutaneous balloon valvotomy for congenital pulmonary stenosis using over-sized balloons. J Am Coll Cardiol 1986;8:909-15.

8 Rao PS. Further observations on the effect of balloon size on the short term and intermediate term results of balloon dilatation of the pulmonary valve. Br Heart $J$ 1988;60:507-11. 